\title{
Inflammatory Mediators for the Diagnosis and Treatment of Sepsis in Early Infancy
}

MALGORZATA A VERBOON-MACIOLEK, STEVEN F. T. THIJSEN, MARIEKE A. C. HEMELS, MARIOLEIN MENSES, ANTON M. VAN LOON, TANNETTE G. KREDIET, LEO J. GERARDS, ANDRE FLEER, HIERONYMUS A. M. VOORBIJ, AND GER T. RIJKERS

Department of Neonatology, University Medical Center [M.A.V.-M., MAC.H., M.M., T.G.K., L.J.G.], Department of Immunology [G.T.R.], Wilhelmina Children's Hospital, 3584 EA Utrecht; Department of Medical Microbiology [S.F.T.T.], Diakonessenhuis, 3582 KE, Utrecht; Departments of Virology [A.M.L.] and Microbiology [A.F.], Eijkman Winkler Institute for Microbiology, Infectious Diseases and Inflammation, 3584 CX Utrecht; Laboratory of Special Chemistry [A.M.V.], University Medical Center, 3584 CX, Utrecht; Department of Immunology [G.T.R.], Wilhelmina Children's Hospital, 3584 EA Utrecht, The Netherlands

\begin{abstract}
Interleukin-6 (IL-6), interleukin-8 (IL-8), and procalcitonin (PCT) are important parameters in the diagnosis of sepsis and for differentiating between viral and bacterial infection in children. We compared the value of IL-6, IL-8, and PCT with C-reactive protein (CRP) in the diagnosis and treatment of late-onset sepsis among infants admitted to the neonatal intensive care unit (group I) and febrile infants admitted to general hospitals from home (group II). Group I was divided into subgroups Ia, positive blood culture (all Gram-positive cocci); Ib, negative blood culture; and Ic, controls. Group II was divided into subgroups IIa, systemic enterovirus infection, and IIb, no enterovirus infection. Enterovirus was identified by real-time (RT) polymerase chain reaction (PCR) and/or by culture in blood and cerebrospinal fluid (CSF). The positive predictive values of IL-6, IL-8, and PCT $(78 \%, 72 \%$, and $83 \%$, respectively) were better than that of CRP (63\%) in the diagnosis of neonatal sepsis. After $48 \mathrm{~h}$ of antibiotic treatment, IL-6 and IL- 8 levels significantly decreased and PCT stabilized in clinically recovered patients, suggesting that these markers may be useful in distinguishing patients in which antibiotic treatment may be discontinued. Among infants of subgroup IIa, 80\%-90\% had normal values of IL-6, IL-8, and PCT, whereas CRP was increased in $40 \%$. In conclusion, IL-6, IL-8, and PCT are better parameters than CRP in the diagnosis and follow-up of neonatal sepsis due to coagulase-negative staphylococci (CoNS) and in the exclusion of bacterial infection among those with enteroviral infection among febrile infants presenting from home. (Pediatr Res 59: 457-461, 2006)
\end{abstract}

$\mathrm{S}$ ystemic infections are responsible for a high hospital admission rate of neonates and young infants and for prolonged hospitalization of infants admitted to neonatal intensive care units (NICUs) $(1,2)$. Nosocomial infections in neonates admitted to NICUs are most frequently caused by Gram-positive cocci, especially CoNS $(2,3)$. The majority of young infants admitted to pediatric wards in the summer months because of high fever and suspected sepsis have community-acquired enteroviral infection $(4,5)$. The clinical symptoms of bacterial and enteroviral sepsis in young infants

Received July 13, 2005; accepted November 1, 2005

Correspondence: M. A. Verboon-Maciolek, M.D., Department of Neonatology, Room KE.04.123.1, University Medical Center, Lundlaan 6, 3584 EA Utrecht, PO Box 85090, 3508 AB Utrecht, The Netherlands; e-mail: M.Verboon-Maciolek@umcutrecht.nl. are usually difficult to distinguish and include fever, temperature instability, irritability, lethargy, apnea, and abdominal distention. Therefore, the differentiation of bacterial from viral sepsis is difficult due to the nonspecific clinical signs and symptoms. Because the consequences of a delay of treatment in cases of bacterial neonatal sepsis may be severe, pediatricians usually start antibiotic treatment promptly when an infection is suspected. The initiation of antibiotic treatment is based on the combination of clinical observations and laboratory results, especially the level of CRP and the ratio between immature neutrophils and total neutrophils (I/T ratio) of the blood film. However, these parameters are far from satisfactory as early laboratory indicators of infection $(6,7)$.

During recent year, several new parameters have been introduced that appear to be more sensitive in detecting bacterial infection $(7,8)$. Cytokines such as IL-6 and IL-8 and PCT, which are induced by lipopolysaccharides or other bacterial compounds, are potentially valuable parameters in the early diagnosis of bacterial sepsis because of their presence already in the early phase (9-15).

We studied the additional value of IL-6, IL-8, and PCT for the diagnosis of sepsis and for the differentiation between bacterial and enteroviral infection in NICU patients and in patients admitted to the pediatric ward of two general hospitals with clinical signs of sepsis and compared the results with CRP levels. Furthermore, we studied the levels of IL-6, IL-8, and PCT after $48 \mathrm{~h}$ of antibiotic treatment as a tool for deciding to discontinue antibiotic treatment earlier than after 7 to $14 \mathrm{~d}$ in patients with confirmed bacterial sepsis and clinical recovery.

\section{METHODS}

Patients. From January 2000 through December 2002, 66 infants with clinical signs of sepsis and 26 infants without signs of infection admitted at the NICU of Wilhelmina Children's Hospital, Utrecht, were enrolled in the Abbreviations: CoNS, coagulase-negative staphylococci; CRP, C-reactive protein; IL-6, interleukin-6; IL-8, interleukin-8; PCT, procalcitonin 
study as well as 19 infants admitted at the pediatric ward of two general hospitals (Diakonessenhuis and Medical Center Mesos, Utrecht) with clinical signs of sepsis, during the period of April 2000 through January 2001. Inclusion criteria for all patients were age $60 \mathrm{~d}$ or younger and two or more of the following clinical symptoms of infection: fever or temperature instability, respiratory distress, poor peripheral circulation, irritability, lethargy, apnea, tachycardia, hypotension, poor feeding, abdominal distention, and diarrhea (16). Gestational age, birth weight, sex, and age at onset of clinical symptoms of infection were analyzed. Plasma levels of IL-6, IL-8, PCT, and CRP were determined at onset of symptoms or at inclusion in the study and at $48-72 \mathrm{~h}$ after onset of symptoms (NICU patients).

Parental informed consent was obtained for each patient entering the study. The study was approved by the Medical Ethical Review Board of the University Medical Center Utrecht.

Laboratory parameters. Standard biochemical and hematological parameters and samples for blood culture $(0.5 \mathrm{~mL})$ and for IL-6, IL-8, PCT, and CRP determinations $(0.5 \mathrm{~mL})$ were obtained by peripheral venous puncture before initiation of antibiotic therapy in infants suspected of sepsis or at the moment of inclusion in the study as control infants. Plasma was separated from the blood cells within $60 \mathrm{~min}$ by centrifugation at $1000 \times \mathrm{g}$ for $10 \mathrm{~min}$ and stored in plastic tubes at $-20^{\circ} \mathrm{C}$ until further use. CRP was measured by rate nephelometry. IL-6 and IL-8 measurements were made using a fully automated chemiluminescence assay (Immulite, Diagnostic Products Corporation). The detection limits of the assay were $1.0 \mathrm{pg} / \mathrm{mL}$ both for IL- 6 and IL-8, as indicated by the manufacturer. PCT was measured by a specific immunoluminometric assay (Lumitest PCT, Brahms Diagnostica GMBH, Berlin, Germany). Blood $(0.5 \mathrm{~mL})$ and CSF for RT-PCR for enteroviruses was collected at onset of symptoms of NICU patients or at admission of patients from general hospitals.

Microbiological examination. Blood, CSF, and urine cultures were performed with the BacT/ALERT automated system (Organon Teknica) with Pedi-Bact pediatric blood culture bottles. Bottles with positive results were subcultured on blood agar plates. Isolates were identified by standard bacteriological methods. When a blood culture was positive within $48 \mathrm{~h}$, it was considered as a true bacteriemia. Besides the blood culture at onset of sepsis and after $48 \mathrm{~h}$, colony-forming units (CFUs) were counted.

Virological examination. Feces and CSF were inoculated on different cell cultures including tertiary monkey kidney cells, human embryonic diploid fibroblasts, and RD cells (derived from human rhabdomyosarcoma). Cultures showing a cytopathic effect suggesting an enteroviral infection were typed by neutralization tests that used pools of antisera and specific antisera, developed at the National Institute of Public Health, RIVM, in The Netherlands (17). RT-PCR for enteroviruses was carried out on blood, feces, and/or CSF as described previously (18). Positive RT-PCR on blood and/or CSF was interpreted as evidence of systemic enteroviral infection (4). Fecal specimens of patients with gastrointestinal symptoms also were investigated for rotavirus and adenovirus by a MAB-based enzyme immunoassay; nasopharyngeal swabs of patients with pulmonary symptoms also were screened by immunofluorescence with MAB for respiratory viruses. All analyses remained negative in this study group.

Statistical analysis. The differences between the various categories of patients in clinical data and laboratory values were analyzed by $t$ test, nonparametric Mann-Whitney test, or Wilcoxon signed ranks test, where appropriate. Receiver operating characteristic (ROC) curves were created for IL-6, IL-8, PCT, and CRP, using MedCalc software (MedCalc 5.00.019, Mariakerke, Belgium). Sensitivity, specificity, positive predictive value (PPV), and negative predictive value (NPV) were calculated for IL-6, IL-8, CRP, PCT, and the combination of IL-6 or IL-8 with CRP, using the cutoff values for IL-6, IL-8, PCT, and CRP resulting from ROC analysis. Exact 95\% confidence intervals were calculated for all the parameters. Statistical significance was assumed for $p<0.05$.

\section{RESULTS}

In total, 111 patients were included in the study: 92 admitted at the NICU (group I) and 19 at the pediatric wards of the two general hospitals (group II). For further analysis, the patients were divided in five subgroups: group Ia, proven bacterial sepsis [CoNS $(n=35)$ or Staphylococcus aureus $(n=2)](n=37)$; group Ib, clinical sepsis (blood culture negative) $(n=29)$; group Ic, infants without symptoms of infection (controls) $(n=26)$; subgroup IIa, proven enterovirus infection based on a positive RT-PCR on blood or CSF or on positive culture of CSF $(n=10)$; subgroup IIb, clinical signs of sepsis, with negative enterovirus PCR on blood or CSF or negative enterovirus culture $(n=9)$.

Enterovirus RT-PCR was performed, in addition to bacterial cultures, on 46 of 92 infants admitted at the NICU from group I: in this group no enteroviral infection was diagnosed.

The clinical characteristics and values for IL-6, IL-8, PCT, and CRP at onset of clinical signs of sepsis or at inclusion in the study are summarized in Table 1 for group I and in Table 2 for group II. There were no significant differences between the subgroups of groups I and II in gestational age, birth weight, male/female ratio, or time at onset of symptoms.

Group I. Diagnostic cutoff values with the optimum sensitivity and specificity derived from the ROC curve were $>60$ $\mathrm{pg} / \mathrm{mL}$ for IL-6, $>50 \mathrm{pg} / \mathrm{mL}$ for IL-8, $>0.5 \mu \mathrm{g} / \mathrm{L}$ for PCT, and $>14 \mathrm{mg} / \mathrm{L}$ for CRP. Sensitivity, specificity, PPV, and NPV for IL-6, IL-8, CRP, PCT, and for the combination of CRP with IL-6 or IL-8 for the diagnosis of sepsis in group I infants are shown in Table 3.

The highest PPV was found for PCT (PPV of 83\%) and the highest NPV was found for IL-8 in combination with CRP (NPV of 92\%) The PPVs of the individual parameters were lowest for CRP. Antibiotic treatment was started in all patients from groups Ia and Ib because of clinical signs suggesting infection. In these patients, IL-6, IL-8, PCT, and CRP were reevaluated after $48 \mathrm{~h}$ of treatment. IL- 6 was reevaluated in 20 of 37 , IL-8 in 25 of 37, PCT in 26 of 37, and CRP in all 37 infants from group Ia; IL-6 and IL-8 were reevaluated in 10 of 29 , PCT in 10 of 29, and CRP in all 29 infants from group Ib.

Table 1. Clinical characteristics and values for IL-6, IL-8, CRP and PCT of infants treated at the neonatal intensive care unit at onset of symptoms of sepsis

\begin{tabular}{lccc}
\hline & Group Ia: proven sepsis $(n=37)$ & Group Ib: clinical sepsis $(n=29)$ & Group Ic: controls $(n=26)$ \\
\hline GA, wk, median (range) & $29(25-40)$ & $29(26-41)$ & $30(26-41)$ \\
BW, g, median (range) & $1300(825-3800)$ & $1200(690-3800)$ & $1400(690-3700)$ \\
Male/female & $19 / 16$ & $14 / 14$ & $18 / 8$ \\
Age at onset, d, median (range) & $12(4-35)$ & $30(3-41)$ & $10(4-24)$ \\
IL-6, pg/mL, median (range) & $1050(1.6-38,855)^{*}$ & $41(22-600)$ & $6(1-56)$ \\
IL-8, pg/mL, median (range) & $279(13-7617)^{*}$ & $15(5-75)^{* *}$ & $30(1-138)$ \\
CRP, mg/L, median (range) & $17(5-119)^{* *}$ & $5(5-14)$ \\
PCT, $\mu \mathrm{g} / \mathrm{L}$, median (range) & $1.0(0.25-64)^{*}$ & $0.29(0.12-1.5)^{* *}$ & $0.15(0.1-0.95)$ \\
\hline
\end{tabular}

$* p<0.05$ vs Ib and Ic; $* * p<0.05$ vs Ic.

GA, gestational age; BW, birth weight. 
Table 2. Clinical characteristics and values for IL-6, IL-8, CRP, and PCT of infants presenting with clinical sepsis at the pediatric wards of two general hospitals

\begin{tabular}{lcc}
\hline & $\begin{array}{c}\text { Subgroup IIa: } \\
\text { enterovirus sepsis } \\
(n=10)\end{array}$ & $\begin{array}{c}\text { Subgroup IIb: } \\
\text { enterovirus sepsis } \\
(n=9)\end{array}$ \\
\hline GA, wk, median (range) & $40(39-42)$ & $40(38-41)$ \\
BW, g, median (range) & $3745(3300-4480)$ & $3450(2760-3860)$ \\
Male/female & $26(5-55)$ & $6 / 3$ \\
Age at onset, d, median (range) & $8(80)$ & $3(1-55)$ \\
Admission during summer/fall, $\mathrm{n}(\%)$ & $\leq 50(\leq 50-210)$ & $7(80)$ \\
IL-6, pg/mL, median (range) & $1(10)$ & $\leq 50(\leq 50-288)$ \\
IL-6, $>60$ pg/mL, n (\%) & $550(\leq 50-917)$ & $5(55)$ \\
IL-8, pg/mL, median (range) & $1(10)$ & $83(\leq 50-7310)$ \\
IL-8, $>50$ pg/mL, n (\%) & $13(5-44)$ & $4(44)$ \\
CRP, mg/mL, median (range) & $4(40)$ & $12(3-98)$ \\
CRP, $>14$ mg/L, n (\%) & $0.17(0.1-0.94)$ & $4(44)$ \\
PCT, $\mu \mathrm{g} / \mathrm{L}$ & $2(20)$ & $0.43(0.12-58)$ \\
PCT, $>0.5 \mu \mathrm{g} / \mathrm{L}, \mathrm{n}(\%)$ & $4(44)$ & \\
\hline
\end{tabular}

GA, gestational age; BW, birth weight.

Table 3. Sensitivity, specificity, PPV, and NPV for IL-6, IL-8, CRP, and PCT for the diagnosis of sepsis in infants admitted to the NICU (cutoff values determined with ROC analysis)

\begin{tabular}{|c|c|c|c|c|c|c|}
\hline & IL-6 $>60 \mathrm{pg} / \mathrm{mL}$ & $\mathrm{IL}-8>50 \mathrm{pg} / \mathrm{mL}$ & $\mathrm{CRP}>14 \mathrm{mg} / \mathrm{L}$ & $\mathrm{PCT}>0.5 \mu \mathrm{g} / \mathrm{L}$ & $\begin{array}{c}\mathrm{IL}-6>60 \mathrm{pg} / \mathrm{mL} \\
\text { and } / \mathrm{or} \\
\mathrm{CRP}>14 \mathrm{mg} / \mathrm{L}\end{array}$ & $\begin{array}{c}\mathrm{IL}-8>50 \mathrm{pg} / \mathrm{mL} \\
\text { and } / \mathrm{or} \\
\mathrm{CRP}>14 \mathrm{mg} / \mathrm{L}\end{array}$ \\
\hline SENS, \% (95\% CI) & $68(50-82)$ & $84(68-94)$ & $65(47-80)$ & $69(51-83)$ & $92(78-98)$ & $97(86-100)$ \\
\hline PPV, \% (95\% CI) & $78(60-91)$ & $72(53-82)$ & $63(46-78)$ & $83(64-94)$ & $67(54-80)$ & $68(54-80)$ \\
\hline NPV, \% (95\% CI) & $65(46-80)$ & $74(48-89)$ & $54(34-72)$ & $68(49-83)$ & $80(52-96)$ & $92(64-100)$ \\
\hline
\end{tabular}

SENS, sensitivity; SPEC, specificity.

The plasma levels of IL-6, IL-8, and PCT at the onset of symptoms were significantly higher in subgroup Ia (with proven sepsis) than in subgroup $\mathrm{Ib}$ (with negative blood culture) and the control group Ic $(p<0.05)$ (Table 1, Fig. 1).

Figure 1 shows that after $48 \mathrm{~h}$ of treatment, the levels of IL-6 and IL- 8 had decreased significantly in subgroup Ia and were comparable with the values of IL-6 and IL-8 in subgroups Ib and Ic. The median levels of PCT were similar at the onset of symptoms and after $48 \mathrm{~h}$ of treatment in subgroups Ia
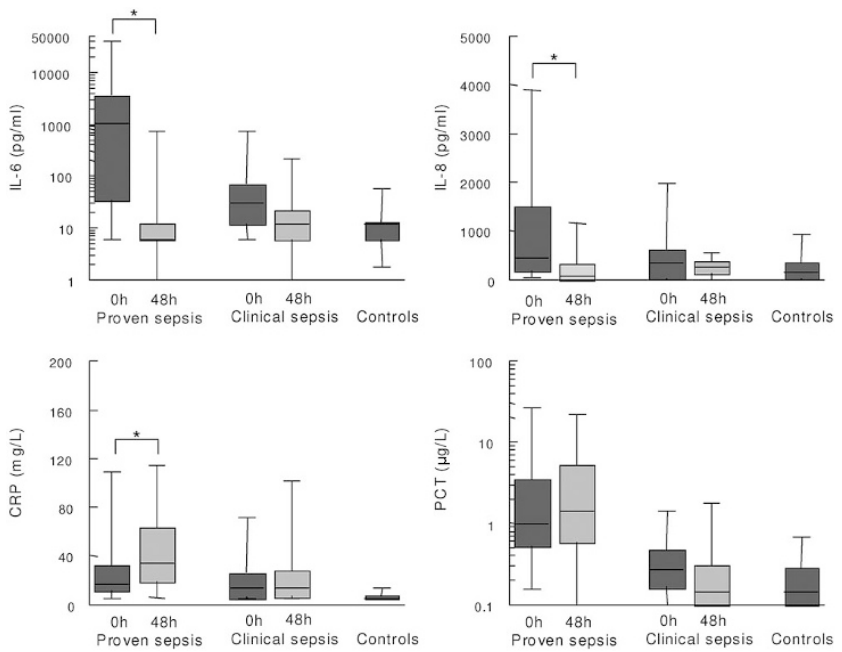

Figure 1. Levels of IL-6, IL-8, PCT, and CRP at the onset of symptoms of infection and after $48 \mathrm{~h}$ of antibiotic treatment in infants admitted to the NICU: proven sepsis $(n=37)$, clinical sepsis $(n=29)$, controls $(n=26)$, ${ }^{*} p$ $<0.05$ between the levels at onset and after $48 \mathrm{~h}$ of treatment. and Ib. In contrast to IL-6, IL-8, and PCT, the values of CRP were not different between subgroups $\mathrm{Ia}$ and $\mathrm{Ib}$ at the onset of infection, although they were significantly higher than in the control group ( $p<0.005)$. After 48 h, CRP had significantly increased in subgroup Ia $(p<0.05)$ (Fig. 1).

Antibiotic treatment was continued for $7-10 \mathrm{~d}$ in all infants with proven sepsis, whereas in patients of subgroup Ib, the antibiotics were discontinued after $3 \mathrm{~d}$ if the blood culture remained negative, the patients were clinically well, and no infection sites were found.

All patients from group I recovered, except for one patient in subgroup Ia. This latter patient needed laparotomy because of necrotizing enterocolitis and died $23 \mathrm{~d}$ after inclusion in the study because of superior vena cava syndrome.

Group II. There were no statistical differences found between various categories (Table 2, Fig. 2) in this group of patients. Enteroviral infections occurred in the summer and fall in eight of 10 patients; in both subgroups of group II, a male predominance was found. Due to the small number of patients in this group, the predictive values for the diagnosis of sepsis or enteroviral infection could not be evaluated.

Table 2 shows that normal median values were found for IL-6, PCT, and CRP for infants in subgroup IIa, with proven enteroviral infection as well as for infants in subgroup IIb, with clinical signs of infection but with negative bacterial blood culture or enterovirus culture or PCR. The median level of IL-8 was below the cutoff value in subgroup IIa but slightly increased in subgroup IIb (Fig. 2.) One infant from subgroup IIa had an increased level of IL-8 (917 pg/mL) and another 

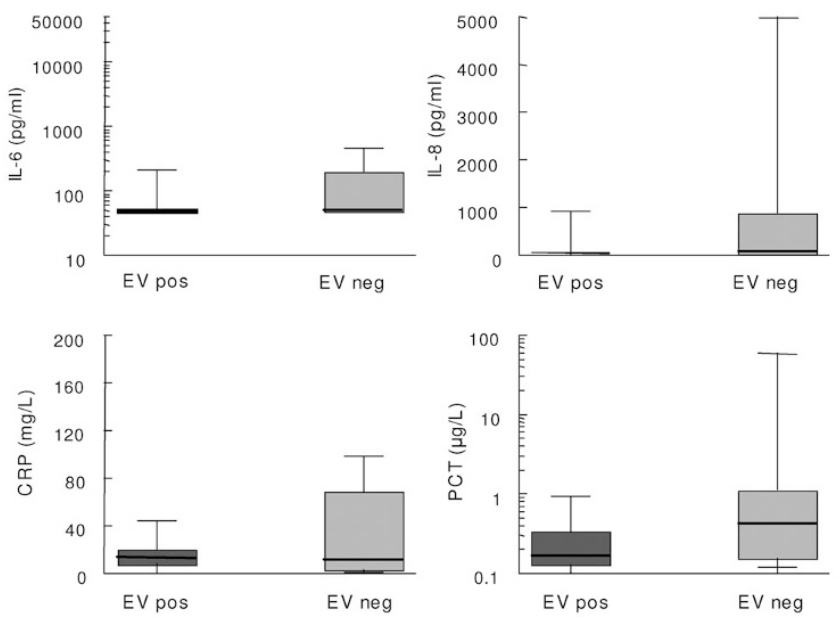

Figure 2. Levels of IL-6, IL-8, PCT, and CRP in infants admitted to two general hospitals with a clinical diagnosis of sepsis. Enterovirus positive (EV pos) $(n=10)$, enterovirus negative (EV neg) $(n=9)$.

infant had an increased levels of IL-6 (210 pg/mL) and PCT $(0.94 \mu \mathrm{g} / \mathrm{L})$. In the infant with increased IL-8, a urinary tract infection was diagnosed in addition to an enteroviral infection. In the infant with increased IL-8 and PCT, no other infectious agent was found. In four of eight infants with enterovirus sepsis, aseptic meningitis was diagnosed (pleocytosis range, 488-4800 leukocytes/ $/ \mathrm{mm}^{3}$ ). IL-6, IL-8 PCT, and CRP levels were normal. In four of nine infants from subgroup IIb (clinical signs of sepsis, diagnosis enteroviral infection negative), the IL-6, IL-8, and PCT levels were above the cutoff values.

The median values of CRP were low in both subgroups, although an increased value above the cutoff value of $14 \mathrm{mg} / \mathrm{L}$ was noted in four of 10 infants from subgroup IIa (one with normal levels of IL-6, IL-8, and PCT) and in four of nine infants from subgroup IIb (three with increased levels of IL-6, IL-8, and PCT). None of the infants from group II had a positive bacterial blood culture. In two infants from subgroup IIb with increased levels of all four parameters, the diagnosis of urinary tract infection was made. These patients were treated with antibiotics, irrespective of the magnitude or change in levels of inflammatory mediators.

\section{DISCUSSION}

These data show that IL-6, IL-8, and PCT are superior to CRP in the diagnosis of late-onset neonatal sepsis due to CoNS and that they have normal values in the majority of infants with systemic enteroviral infection.

Previous studies in adults and children have demonstrated the important role of IL-6, IL-8, and PCT in the diagnosis of sepsis $(19,20)$. Most studies on new parameters performed in infants were limited to cases with clinical signs of early-onset sepsis (within $48 \mathrm{~h}$ after birth) $(7,12,13,21,22)$. IL-6 or IL-8 in combination with CRP was found to be a good marker of bacterial infection in neonates and adds important information if one is considering withholding or stopping antibiotic therapy $(10,15,23)$. Results of studies on the use of PCT as an early marker of neonatal sepsis are contradictory. A significant increase was found in both term infants and preterm infants with sepsis $(8,9,22,24)$. The diagnosis of sepsis is difficult in neonates admitted to the NICU due to nonspecific clinical signs. Therefore, reliable indicators of sepsis would be helpful in an accurate diagnosis, resulting in decreased unnecessary use of antibiotics.

Our study was carried out in 37 preterm infants with documented sepsis (subgroup Ia) due to Gram-positive cocci; in 35 patients, sepsis was due to CoNS. A recently reported study showed that even preterm infants are able to produce IL-6 and IL-8 in case of infection (25). Another report suggested that coagulase-negative infections may probably cause a weaker inflammatory response than infections with other microorganisms $(10,26)$. The median levels of IL-6 and IL-8 in our population with CoNS sepsis were much higher than reported before, and the levels in two infants with $S$. aureus sepsis did not differ from the total subgroup Ia. The median levels of PCT in infants with sepsis due to CoNS were lower than in studies in critically ill children (8). The PPV was highest $(83 \%)$ for PCT, whereas the NPV was highest (74\%) for IL-8. In agreement with the results of a recent study on infants with early-onset sepsis, the combination of IL-8 with CRP also improved the sensitivity and NPV in our NICU population (23).

At present, CRP is widely used as a parameter in the diagnosis of sepsis because it is easy to determine and not very costly (6). Using CRP only, we could not distinguish between infants with positive or negative blood culture. IL-8 or PCT values would be a better choice; however, none of these parameters had an excellent predictive values. Furthermore, assays are more expensive and the determinations of cytokines more elaborate. For these reasons, many hospital laboratories are not able to perform these assays.

The use of cytokines and PCT in the follow-up of treatment with antibiotics has been previously advocated $(8,10,13,15,23)$. In our study, we found a rapid decrease after $48 \mathrm{~h}$ of IL-6 and IL-8 levels in infants with uneventful clinical recovery. CRP levels, however, showed an increase after $48 \mathrm{~h}$ of treatment in these infants. IL- 6 drives the acute phase response based on IL-6 response elements within the promotor region of CRP and thus the increase in CRP follows that of IL-6 (27). Furthermore, CRP has a much longer half-life (6,7). In an earlier study, we have found that in infants with CoNS sepsis, CRP normalized after 5-6 d (3).

In contrast to CRP, PCT levels stabilized after $48 \mathrm{~h}$ of treatment and, in agreement with previous studies, should decrease to their normal values after 2-3 d. For this reason, PCT may be useful as a prognostic marker of infection (8). Because we found an excellent NPV (NPV of 92\%) for the combination of IL-8 and CRP and a significant decrease in IL-8 and IL-6 after $48 \mathrm{~h}$ of treatment in septic infants, these parameters may be useful in the follow-up of treatment of infants with clinical signs of sepsis and proven CoNS sepsis to aid in the decision to discontinue antibiotic treatment early in those infants who have clinically recovered. This strategy may help reduce the burden of antibiotic use and diminish the threat of emerging multiresistant microorganisms in the NICU. 
In the group of infants who presented to the pediatric wards of the two general hospitals with clinical signs of sepsis, systemic enteroviral infection was confirmed in 53\%. Enteroviral infection is frequently diagnosed in infants admitted to the hospital, especially during the summer months $(1,4,28)$. The median age at onset of symptoms in the enteroviral group was much higher than in the group without enteroviral infection (26 and $3 \mathrm{~d}$, respectively). In this population, it would be interesting to be able to differentiate immediately between infants with a bacterial infection or a possible enteroviral infection before the culture or PCR results are known. In this way, it would be possible to refrain from antibiotic treatment of infants who later appear to have an enterovirus infection.

Increased CRP concentrations have been also observed in noninfected clinical conditions and viral infections (6). In contrast to CRP, low values of PCT and/or IL-6 were found in infants infected with adenovirus, rotavirus, or respiratory syncytial virus (29-31). In particular, PCT, a parameter that is both stable and simple to determine, was repeatedly found to be better than CRP in the diagnosis of viral infection.

Our results showed that in $90 \%$ of the infants with enteroviral sepsis, the levels of IL- 6 and IL- 8 were below the cutoff value and in $80 \%$ of the infants the levels of PCT were below the cutoff value, whereas the CRP was increased in $40 \%$ of them. On the other hand, in about $70 \%$ of the infants without proven enteroviral sepsis, at least one of the parameters was increased above the cutoff value. Two of these patients had urinary tract infection; in the other six infants, a diagnosis of viral of bacterial infection could not be confirmed.

In conclusion, our results suggest that IL-6, IL-8, and PCT are better diagnostic tools in the diagnosis of bacterial sepsis caused by CoNS than CRP, but none of them can be used as a gold standard. Measurements of IL-8 in combination with CRP improved sensitivity and the NPV that can reduce unnecessary antibiotic therapy in infants without infection. Rapid decrease in IL-6 and IL-8 levels to below the cutoff value after antibiotic treatment in cases with proven sepsis caused by CoNS may justify the early discontinuation of antibiotic treatment in clinically recovered patients. Levels of IL-6, IL-8, and PCT are normal in the majority of infants with systemic enteroviral infection and may be more useful than CRP in the decision to start or to refrain from antibiotic treatment in infants presenting with clinical signs of systemic infection in general hospitals.

Acknowledgment. The authors thank Cuno Uiterwaal for his assistance with statistical analysis of the data.

\section{REFERENCES}

1. Dagan R 1996 Nonpolio enteroviruses and the febrile young infant: epidemiologic, clinical and diagnostic aspects. Pediatr Infect Dis J 5:67-71

2. Stoll BJ, Hansen N, Fanaroff AA, Wright LL, Carlo WA, Ehrenkranz RA, Lemons JA, Donovan EF, Stark AR, Tyson JE, Oh W, Bauer CR, Korones SB, Shankaran S, Laptook AR, Stevenson DK, Papile LA, Poole WK 2002 Late-onset sepsis in very low birth weight neonates: the experience of the NICHD Neonatal Research Network. Pediatrics 110:285-291

3. Krediet TG, Jones ME, Gerards LJ, Fleer A 1999 Clinical outcome of cephalothin versus vancomycin therapy in the treatment of coagulase-negative staphylococcal septicemia in neonates: relation to methicillin resistance and mec A gene carriage of blood isolates. Pediatrics 103:E29

4. Rotbart HA, McCracken GH Jr, Whitley RJ, Modlin JF, Cascino M, Shah S, Blum D 1999 Clinical significance of enteroviruses in serious summer febrile illnesses of children. Pediatr Infect Dis J 18:869-874

5. Verboon-Maciolek MA, Nijhuis M, van Loon AM, van Maarssenveen N, van Wieringen H, Pekelharing-Berghuis MA, Krediet TG, Gerards LJ, Fleer A, Diepersloot RJ, Thijsen SF 2003 Diagnosis of enterovirus infection in the first 2 months of life by real-time polymerase chain reaction. Clin Infect Dis 37:1-6

6. Jaye DL, Waites KB 1997 Clinical applications of C-reactive protein in pediatrics. Pediatr Infect Dis J. 16:735-746

7. Ng PC 2004 Diagnostic markers of infection in neonates. Arch Dis Child Fetal Neonatal Ed 89:F229-F235

8. van Rossum AM, Wulkan RW, Oudesluys-Murphy AM 2004 Procalcitonin as an early marker of infection in neonates and children. Lancet Infect Dis 4:620-630

9. Chiesa C, Panero A, Rossi N, Stegagno M, De Giusti M, Osborn JF, Pacifico L 1998 Reliability of procalcitonin concentrations for the diagnosis of sepsis in critically ill neonates. Clin Infect Dis 26:664-672

10. Franz AR, Steinbach G, Kron M, Pohlandt F 1999 Reduction of unnecessary antibiotic therapy in newborn infants using interleukin- 8 and C-reactive protein as markers of bacterial infections. Pediatrics 104:447-453

11. Gendrel D, Bohuon C 2000 Procalcitonin as a marker of bacterial infection. Pediatr Infect Dis J 19:679-687

12. Martin H, Olander B, Norman M 2001 Reactive hyperemia and interleukin 6 , interleukin 8, and tumor necrosis factor-alpha in the diagnosis of early-onset neonatal sepsis. Pediatrics 108:E61

13. Mehr S, Doyle LW 2000 Cytokines as markers of bacterial sepsis in newborn infants: a review. Pediatr Infect Dis J 19:879-887

14. Mehr SS, Doyle LW, Rice GE, Vervaart P, Henschke P 2001 Interleukin-6 and interleukin-8 in newborn bacterial infection. Am J Perinatol 18:313-324

15. Ng PC, Cheng SH, Chui KM, Fok TF, Wong MY, Wong W, Wong RP, Cheung KL 1997 Diagnosis of late onset neonatal sepsis with cytokines, adhesion molecule, and $\mathrm{C}$-reactive protein in preterm very low birthweight infants. Arch Dis Child Fetal Neonatal Ed 77:F221-F227

16. Tollner U 1982 Early diagnosis of septicaemia in the newborn: clinical studies and sepsis score. Eur J Pediatr 138:331-337

17. van Loon AM, Cleator GC, Ras A 1999 External quality assessment of enterovirus detection and typing. European Union Concerted Action on Virus Meningitis and Encephalitis. Bull World Health Organ 77:217-223

18. Nijhuis M, van Maarseveen N, Schuurman R, Verkuijlen S, de Vos M, Hendriksen K, van Loon AM 2002 Rapid and sensitive routine detection of all members of the genus enterovirus in different clinical specimens by real-time PCR. J Clin Microbiol 40:3666-3670

19. Engel A, Mack E, Kern P, Kern WV 1998 An analysis of interleukin-8, interleukin-6 and C-reactive protein serum concentrations to predict fever, gram-negative bacteremia and complicated infection in neutropenic cancer patients. Infection 26:213221

20. Lin KJ, Lin J, Hanasawa K, Tani T, Kodama M 2000 Interleukin-8 as a predictor of the severity of bacteremia and infectious disease. Shock 14:95-100

21. Berner R, Niemeyer CM, Leititis JU, Funke A, Schwab C, Rau U, Richter K, Tawfeek MS, Clad A, Brandis M 1998 Plasma levels and gene expression of granulocyte colony-stimulating factor, tumor necrosis factor-alpha, interleukin (IL)1beta, IL-6, IL-8, and soluble intercellular adhesion molecule-1 in neonatal early onset sepsis. Pediatr Res 44:469-477

22. Resch B, Gusenleitner W, Muller WD 2003 Procalcitonin and interleukin-6 in the diagnosis of early-onset sepsis of the neonate. Acta Paediatr 92:243-245

23. Franz AR, Bauer K, Schalk A, Garland SM, Bowman ED, Rex K, Nyholm C, Norman M, Bougatef A, Kron M, Mihatsch WA, Pohlandt F; International IL-8 Study Group 2004 Measurement of interleukin 8 in combination with C-reactive protein reduced unnecessary antibiotic therapy in newborn infants: a multicenter, randomized, controlled trial. Pediatrics 114:1-8.

24. Monneret G, Labaune JM, Isaac C, Bienvenu F, Putet G, Bienvenu J 1997 Procalcitonin and C-reactive protein levels in neonatal infections. Acta Paediatr 86:209212

25. Schultz C, Rott C, Temming P, Schlenke P, Moller JC, Bucsky P 2002 Enhanced interleukin-6 and interleukin-8 synthesis in term and preterm infants. Pediatr Res $51: 317-322$

26. Laborada G, Rego M, Jain A, Guliano M, Stavola J, Ballabh P, Krauss AN, Auld PA, Nesin M 2003 Diagnostic value of cytokines and C-reactive protein in the first 24 hours of neonatal sepsis. Am J Perinatol 20:491-501

27. Black S, Kushner I, Samols D 2004 C-reactive protein. J Biol Chem 279:48487-90

28. Byington CL, Taggart EW, Carroll KC, Hillyard DR 1999 A polymerase chain reaction-based epidemiologic investigation of the incidence of nonpolio enteroviral infections in febrile and afebrile infants 90 days and younger. Pediatrics 103:E27

29. Gendrel D, Raymond J, Coste J, Moulin F, Lorrot M, Guerin S, Ravilly S, Lefevre H, Royer C, Lacombe C, Palmer P, Bohuon C 1999 Comparison of procalcitonin with C-reactive protein, interleukin 6 and interferon-alpha for differentiation of bacterial vs. viral infections. Pediatr Infect Dis J 18:875-881

30. Korczowski B, Szybist W 2004 Serum procalcitonin and C-reactive protein in children with diarrhoea of various aetiologies. Acta Paediatr 93:169-173

31. Resch B, Gusenleitner W, Muller W 2003 Procalcitonin, interleukin-6, C-reactive protein and leukocyte counts in infants with bronchiolitis. Pediatr Infect Dis J 22:475-476 